\title{
Weight-status Related Differences in Reflective and Impulsive Determinants of Physical Activity in Youngsters (8-18 years old)
}

\author{
Gill A. ten Hoor*, Guy Plasqui ${ }^{\dagger}$, Gerjo Kok*, Annemie M. W. J. Schols, Robert A. C. \\ Ruiter*, Stef P. J. Kremers§ ${ }^{\S}$ Gjalt-Jorn Y. Peters"l and Anita C. E. Vreugdenhilף
}

\begin{abstract}
Objective: To investigate associations between weight status and physical activity, psychosocial impulsive, and reflective determinants of exercise behavior in youngsters (8-18 years old), distinguishing between strength exercises and aerobic exercises.

Method: Cross-sectional survey of 133 youngsters (89 girls - 59 youngsters who are being treated for obesity in an outpatient lifestyle intervention program, plus 74 youngsters from the general population). In order to identify reflective determinants, participants completed questionnaires. For the impulsive determinants, participants completed two computerized reaction time sorting-tasks ('Implicit Association Tests').

Results: Exercise intentions, including those for aerobic and strength exercises, were positively correlated with BMI z-scores. Youngsters with a higher BMI z-score often reported that their friends think they should exercise and were more confident that they could exercise more if they wanted to. No other determinants, including impulsive determinants, were correlated with BMI z-scores.

Conclusion: In terms of reflective determinants, few differences were found between youngsters with higher BMI Z-scores as compared to youngsters with lower BMI z-scores. There was no significant correlation between $\mathrm{BMI} z$-score and the impulsive determinants of aerobic versus strength exercise. This suggests that youngsters, independent from weight status feel that they could be reached by the same kind of physical activity intervention.
\end{abstract}

Keywords: physical activity; reflective determinants; impulsive determinants; children and adolescents; overweight and obesity; strength exercises; dual process

\section{Introduction}

Obesity is a global problem and is no longer a disease that affects adults only (Washington, 2008). In children and adolescents who are obese, not only metabolic and cardiovascular health is impaired (TNO, 2011), but psychological well-being is often decreased as well (Gately, Cooke, Butterly, Mackreth, \& Carroll, 2000; Van der Baan, Nollet, Weller, Benninga, \& Van Aalderen, 2010).

Three major factors contribute to childhood obesity: genetic predisposition, unfavorable environmental conditions, and a disturbed energy balance/imbalance of

\footnotetext{
* Department of Work and Social Psychology, Maastricht University, Maastricht, NL

Department of Nutrition and Movement Sciences, Research School NUTRIM, Maastricht University Medical Center, Maastricht, NL

* Department of Respiratory Medicine, Research School NUTRIM, Maastricht University Medical Centre, Maastricht, NL

§ Department of Health Promotion, Research School NUTRIM,
}

energy homeostasis (Ebbeling, Pawlak, \& Ludwig, 2002). This is the result of a combination of a high energy intake and relatively low energy expenditure (Kremers, Visscher, Seidell, Van Mechelen, \& Brug, 2005). In line with these findings, physical activity programs have been introduced to combat overweight and obesity. However, school-based meta-analyses show that these interventions have little effect on body weight or body mass index (BMI; Harris, Kuramoto, Schulzer, \& Retallack, 2009), blood pressure (Guerra, Nobre, Silveira, \& Taddei, 2013), or physical activity level (Metcalf, Henley, \& Wilkin, 2012).

\footnotetext{
Maastricht University Medical Center, Maastricht, NL

\| Department of Methodology and Statistics, Open University, Heerlen, NL

" Centre for Overweight Adolescent and Children's Healthcare $(\mathrm{COACH})$ Department of Pediatrics, Research School NUTRIM, Maastricht University Medical Center, Maastricht, NL

Corresponding author: Gill A. ten Hoor

(Gill.tenHoor@MaastrichtUniversity.nl)
} 


\section{Psychosocial determinants of physical activity}

To develop more effective intervention programs targeting youngsters who are overweight or obese, a detailed study of the psychosocial determinants (i.e. those psychological constructs theoretically assumed to cause behavior) of physical activity is warranted (De Bourdeaudhuij et al., 2005; Peters, 2014). Earlier, we have argued that when it comes to physical activity, we have to bear in mind that overweight and obese youngsters are not 'general normalweight' youngsters and hence different interventions might be needed (Ten Hoor et al., 2014). Our knowledge about these psychosocial determinants of physical activity in populations that are overweight or obese is limited, especially with respect to youngsters who are obese (Liao et al. 2012). Trost et al. (2001) expected differences in physical activity determinants between youngsters who are and who are not obese, but found only a lower exercise self-efficacy for youngsters who are obese. Additionally, Craeynest et al. (2005) found no differences at all in reflective and impulsive attitudes.

In this study, the first aim is to map (both reflective and impulsive) determinants of physical activity and to examine whether the resulting determinant structure varies with weight status.

\section{Reflective and Impulsive Associations}

Behavior change programs are most effective when the new behavior is achievable (Montaño \& Kasprzyk, 2015; Bartholomew et al., 2016) and rewarding (Ryan \& Deci, 2002; Rhodes, Fiala, \& Conner, 2009). So far, the few studies carried out that have investigated determinants of physical activity in youngsters with obesity have identified environmental factors, general quality of life, perceived competence (Morgan, Okely, Cliff, Jones, \& Baur, 2008), attitudes (perceived benefits and barriers), social influences, and self-efficacy (Deforche, De Bourdeaudhuij, Tanghe, Hills, \& Bode, 2004; Trost, Kerr, Ward, \& Pate, 2001). However, all these determinants are so-called 'reflective' determinants, whereas contemporary dual process theories suggest that human behavior is a product of both reflective (rule based) as well as unconscious (impulsive) determinants (Strack \& Deutch, 2004). A person's behavior is determined by the relative strength of impulsive and reflective determinants in the sense that stronger determinants influence behavior more than the weaker ones (Strack \& Deutch, 2004). In order to understand physical activity behavior, it is necessary to measure both the reflective and impulsive determinants. Reflective determinants can be measured by self-reports and involve attitudes, norms, perceived behavioral control and self-image, influencing behavior through intention (Liao et al., 2012). Impulsive determinants are commonly measured indirectly, for example by means of reaction time tasks such as the Implicit Association Test (IAT; Greenwald, McGhee, \& Schwartz, 1998), which do not rely on self-report but rather use reaction times to measure implicit associations, for example, between a concept and an evaluative dimension. Such automatic determinants have been shown to explain variance in behavior that remains unexplained by reflective measures (Strack \& Deutsch, 2004). Craeynest, et al. (2005) reported no differences in implicit associa- tions towards physical activity between youngsters with and without obesity. However, no distinction was made between strength and aerobic exercises in their study.

\section{Aerobic and strength exercises}

Youngsters (here defined as 8-18 year olds) who are overweight or obese can often not compete with normalweight youngsters when it comes to aerobic exercises (Faigenbaum et al., 2009). Strength exercises - defined as exercises where an individual is working against a wide range of resistive loads - may be easier for youngsters who are overweight or obese, and with that easier to comply with (Riddiford-Harland, Steele, \& Baur, 2006; Colella, Morano, Robazza, \& Bortoli, 2009; Ten Hoor, Plasqui, Schols \& Kok, 2014; Ten Hoor et al., 2016; Ten Hoor et al., 2017a). These youngsters are stronger in an absolute sense than normal weight youngsters and perform better in strength- related exercises than aerobic exercises (ten Hoor, 2017b). Furthermore, being better in strength exercises might trigger the intrinsic motivation to continue exercising (Ten Hoor et al., 2014, 2016).

\section{Materials and Methods}

In the current study, we investigated associations between weight status and physical activity, and psychosocial determinants. We included measures of strength and aerobic exercises (Ten Hoor et al., 2014, 2016), and impulsive and reflective determinants (Houben $\&$ Wiers, 2008). Each child's BMI was recoded into a BMI z-score (this is the BMI score but then age and gender specific, compared to the national reference population; Cole, Bellizzi, Flegal \& Dietz, 2000; Cole, Flegal, Nicholls, \& Jackson, 2007). Although use of the term 'obesity' implies dichotomization of youngsters into 'obese' and 'non-obese' youngsters, the underlying variable is continuous; in our study we will refer to this continuous underlying variable as weight status. For descriptive purposes, we used the cut off points as defined by the WHO Growth reference 5-18 years, to determine weight status (BMI z-score $<1$ = normal weight, $>1=$ overweight/obese. All research materials, data, syntax files, and output files are available in Additional File 1.

\section{Participants}

Our sample consists of youngsters who are being treated for obesity in an outpatient lifestyle intervention program, plus youngsters from the general population. In total, 133 youngsters between 8-18 years old participated in this study (89 girls). Fifty-nine youngsters were recruited from the Maastricht University Medical Centre for Overweight Adolescent and Children's Healthcare (COACH). (44\% of the total study population; Mean age $( \pm S D)=12 \pm 3$ years; Mean BMI z-score $=3.3$ ). From these youngsters, 2 were normal weight (BMI z-score between 0-1 - see also 'analysis'), 5 were overweight (BMI z-score between 1-2), and 52 were obese (BMI Z-score $>2$ : cut off points as defined by the WHO growth reference 5-19 years. To recruit a group representative of the general population, 74 youngsters (mean age $=15 \pm 2$ years; BMI z-score $( \pm S D)=0.2 \pm$ 1.2) were randomly recruited through Flycatcher, a Dutch online panel (http://flycatcher.eu/eng/home). Of this group, 3 were underweight (BMI z-score below -2); 53 
were normal weight, 13 overweight (17.6\%), and 5 were obese $(6.7 \%)$. The Flycatcher panel consists of 16.000 individuals and is representative of the Dutch population (ISO 26362 Dutch quality label, certifying that the panel can be used for social-scientific research). There were only a few individuals younger than 12 years old on the Flycatcher panel, whereas the age of the youngsters with obesity ranged from 8-18 years old.

\section{Procedure}

In our cross-sectional study, participants were invited to participate in a short, online computerized task and to complete a questionnaire ( 10 minutes). At the beginning of the study, participants were informed about the procedures but not about the content or aim of the study in order to minimize social desirability effects. The youngsters from $\mathrm{COACH}$ and their parents were informed about the study in a letter and invited to participate during their monthly visit to the outpatient clinic. After parental approval was obtained, the online panel (Flycatcher) group received an invitation to participate via e-mail. After first providing informed consent (by clicking on the appropriate button for the online panel; for the $\mathrm{COACH}$ group by signing the informed consent form), two implicit association tasks (IATs) were performed to measure whether participants had a stronger implicit association with 1) 'physical activity' as compared to 'no physical activity' and 2) 'strength exercises' as compared to 'aerobic exercises' (see Measures). Findings by Houben and Wiers (2008) showed that IAT outcomes do not vary systematically with respect to setting or assessment software.

On completion of the IATs, participants received a questionnaire in which demographics and reflective determinants were measured. Reflective determinants were measured after the IATs because these questions may influence impulsive determinants. Finally, the participants were thanked and debriefed. All study materials and methods were pilot tested to make sure that both the implicit tests and explicit questionnaires could be clearly understood. This study was approved by the Medical Ethics Committee of Maastricht University Medical Center+ (METC12-4-048), and the Research Ethics Board of the Faculty of Psychology and Neuroscience, Maastricht University (ECP-113-10-04-2012).

\section{Measures}

The implicit association test

In this study, two Implicit Association Tests (IATs; [26]) were completed. The first measured whether participants implicitly preferred physical inactivity or physical activity. In the second IAT, we measured preferences for either aerobic, or strength exercises. The IAT is a computerized response latency measure that rests on the assumption that the more strongly two concepts are associated with each other, the faster and more accurately they can be paired together. In Figure $\mathbf{1}$ (schematic display of seven computer screens) the IAT procedure is explained. The IAT consisted of five practice blocks, and two trial blocks. In the first practice block (first picture of Figure 1), participants learned to respond to attribute pictures (appearing in the center of the computer screen) by classifying these

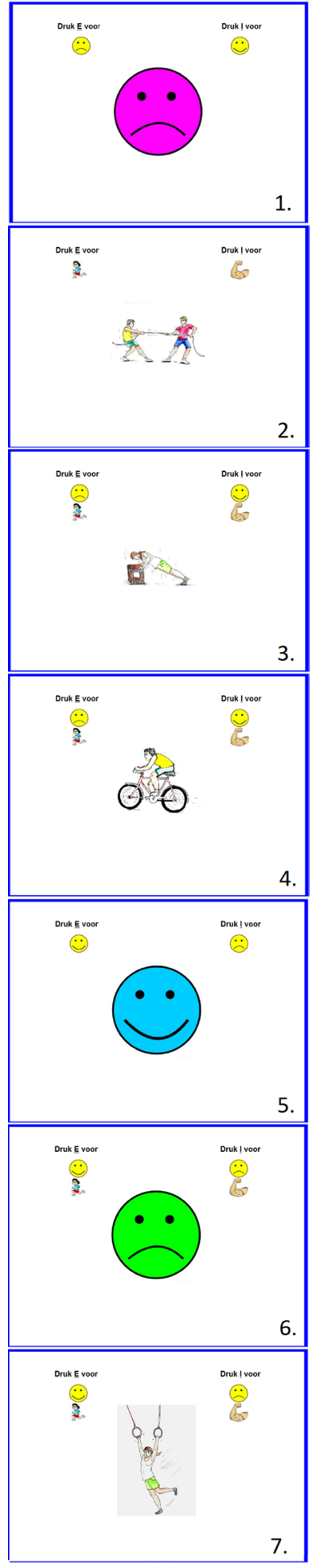

Figure 1: Phases in the Implicit Association Task.

pictures into two categories. In this study, the attribute categories were a picture of a happy and sad emoticon, which were positioned on the left and right side at the top of a computer screen. The attribute pictures that appeared one by one in the center of the computer screen had to be classified into the attribute categories with either the left (E) or right (I) response key. In this way, pictures were linked to relevant concepts. The instruction for participants was to assign the pictures as quickly and as accurately as possible to the correct category by pressing the appropriate response key. The assignment of the left key (E) and right 
key (I) was counterbalanced across participants. With the practice blocks, all images were linked to the relevant concepts. In practice block 2 (picture 2), participants continued categorizing pictures, but now they had to sort pictures of physical activity and physical inactivity into the correct category (in the first IAT; in the second IAT, pictures of aerobic exercises and strength exercises were used). In practice block 3 (picture 3), and test block 4 (picture 4), youngsters continued to assign pictures to the correct category, but now the categories of block 1 and 2 were combined. Reaction times in block 4 were used to calculate one's implicit association. In practice block 5 (picture 5), youngsters responded again to happy and sad emoticon, but now, the emoticons were mirrored (contrary to block $1,2,3,4$, the happy emoticon was on the right, and the sad emoticon on the left). In practice block 6 and test block 7 (picture 6 and 7), the pictures of physical activity and physical inactivity (or aerobic exercises and strength exercises in IAT 2) were added, but not mirrored. Where in block 3 and 4 the picture of aerobic exercises was combined with a sad emoticon, it was now combined with a happy emoticon. Where in block 3 and 4 the picture of physical activity (or strength exercises) was combined with a happy emoticon, this was now combined with a sad emoticon. Based on the difference in mean sorting reaction time between block 4 (happy/physically active vs. sad/physically inactive) and block 7 (sad/physically active vs. happy/physically inactive), corrected for incorrect responses, a difference score was calculated based on the d-600 algorithm (Greenwald, Nosek \& Banaji, 2003); see also SPSS syntax in additional file 1). For the first IAT, a calculated difference score $<0$ reflected a more positive implicit reaction to physical inactivity compared to physical activity. A score $>0$ reflected a more positive implicit reaction to physical activity compared with physical inactivity. A score of 0 reflects no, or ambivalent preferences for both physical activity and physical inactivity. For the second IAT, a score $<0$ means a more positive association with aerobic exercises, and a score $>0$ a more positive association with strength exercises.

\section{The Questionnaire}

Demographics (gender, age, height, and weight), and reflective determinants of physical activity, strength exercises and aerobic exercises were measured using a self-report questionnaire. All items were measured on a 100-point visual analogue scale, except the demographics, BMI, how often they exercised, and self-image. When needed, scores were recoded such that a higher score reflected more agreement with the variable. Scores on items that measured the same construct were averaged into one scale when the internal consistency was sufficient (alpha $>$.60). The questionnaire about the reflective determinants contained the variables listed below, derived from the Reasoned Action Approach, and the Integrated Behavioral Model (Montaño \& Kasprzyk, 2015). For all questions, pictures were added to make sure that the children understood what was meant by the question (see Additional File 1: Complete Study Design).

\section{Self-image}

Questions were asked about self-image: 1) "do you see yourself more as a physically active person" (score $=1$ ) or "a non-physically active person" (score $=2$ ), and 2) "do you see yourself more as someone more suited to aerobic exercises" (score $=1$ ) or "strength exercises" ( score $=2$ ).

\section{Attitude}

Participants' evaluations of 1) physical activity, 2) physical inactivity, 3) aerobic exercises, and 4) strength exercises, were each measured with two unipolar sematic-differentials with the labels "unpleasant-pleasant" and "badgood".

\section{Subjective norms}

Two items measured the extent to which participants believed important others think they should exercise: "My parents want me to exercise" and "My friends want me to exercise". Response categories ranged from "absolutely disagree" to "absolutely agree".

\section{Perceived behavioral control and intention}

For 1) physical activity, 2) aerobic exercises, and 3) strength exercises, a total of three questions were asked about perceived behavioral control: "If you want to, could you be: 1) more physically active 2) carry out more aerobic exercises, and 3) carry out more strength exercises", and three questions about the intention: "Are you going to be 1) more physically active, 2) carrying out more aerobic exercises, and 3) carrying out more strength exercises". Response categories ranged from "absolutely disagree" to "absolutely agree".

\section{Physical activity behavior}

Participants were asked to report: 1) how often they exercised per week and 2) how many hours they spent exercising every time they exercised. From these reports, we calculated how many hours per week were spent exercising.

\section{Analyses}

IBM SPSS statistics 20 was used for data preparation and R ( $R$ Core team, 2014) was used for data analysis. To measure performance on the implicit association tests, d-600 scores were calculated using the d-600 algorithm (Greenwald et al., 2003; see also the SPSS syntax file in Additional File 1). First, as a crude approximation of matching, we examined the difference between participants who would be classified as overweight/obese (BMI z-score $\geq 1$ ) in the general and clinical samples (World Health Organization, 2015). Subsequently, to examine whether determinants of physical activity differ depending on BMI z-score, correlations (and 80\% confidence intervals) were computed between BMI z-scores and attitudes, subjective norms, perceived behavioral controls, intentions, and impulsive determinants. We report both $80 \%$ confidence intervals of effect sizes (following Cohen's (1990) recommendation as well as to prevent reading of the confidence intervals as 'significance testing boundaries', a problem of 95\% confidence intervals) 
and Null Hypothesis Significance Testing (NHST) outcomes, based on the problems reported with NHST (e.g., Masicampo \& Lalande, 2012)) and pleas to remedy this problematic approach (e.g., Denis, 2003).

\section{Results}

Youngsters participating in the outpatient lifestyle intervention program $(\mathrm{COACH})$ might have been positively influenced by their program. Therefore (as a crude approximation of matching) before we executed correlational analyses for the total group, we split up the participants in three groups: the overweight and obese participants from $\mathrm{COACH}$, the overweight and obese participants from the online panel (BMI z-score $>1$ ), and the rest of the general sample (BMI z-score $>=1$ ). After that, we tested the differences between the three groups with regard to the demographic, reflective and impulsive determinants (see Table 1). The highest difference among the three subgroups has a $p$-value $=.02$ (uncorrected for multiple testing; see Additional File 1). We therefore concluded that there does not seem to be a systematic difference between the three subsamples.

Combining the $\mathrm{COACH}$ sample with the participants from the general sample (from Flycatcher) resulted in a final sample where the BMI z-score was bimodally distributed (see Figure 2). No associations with BMI z-scores were found for gender (Cohen's $d=.19$ [-.17, .55], $p=.30$ ). Because the (mainly overweight and obese) participants from the $\mathrm{COACH}$ clinic were younger than the participants from the online panel, BMI z-score decreased with age. Therefore, when computing the correlation coefficients with BMI Z-score, all variables were first corrected for age (besides the already for age corrected BMI z-score). Interested readers can refer to the uncorrected scores and the analyses per subgroup in Appendix 1.

BMI z-scores were not correlated with attitudes towards physical activity $(r=-.05[-.22, .12], p=.75)$, physical inactivity $(r=.06[-.11, .23], p=.71)$, strength exercises $(r=-.02[-.19, .15], p=.84)$, or aerobic exercises $(r=$ $-.09[-.26, .08], p=.48)$ (see Figure 3). Although BMI

Table 1: Mean Scores of the Flycatcher Subsamples, and the COACH Sample, as a Crude Approximation of Matching.

\begin{tabular}{lrrr} 
MEANS & Flycatcher normal weight & Flycatcher overweight & COACH \\
\hline $\mathrm{N}$ & 56 & 18 & 59 \\
Age (year) & 15.82 & 15.17 & 12.14 \\
Height (cm) & 173.46 & 167.83 & 155.28 \\
Weight (kg) & 58.45 & 71.78 & 77.40 \\
BMI Z-score & -0.28 & 1.85 & 3.25 \\
Self-image (1 = no PA, 2 = PA) & 1.54 & 1.44 & 1.64 \\
Self-image (1 = aerobic, 2 = strength) & 1.38 & 1.22 & 1.26 \\
d-600 (no PA - PA)* & -0.24 & -0.24 & -0.08 \\
d-600 (Aerobic -Strength)* & 0.02 & 0.10 & 0.07 \\
Attitude PA (1-100) & 72.86 & 76.06 & 77.56 \\
Attitude no PA (1-100) & 56.33 & 62.72 & 41.67 \\
Attitude Aerobic (1-100) & 74.16 & 74.28 & 76.00 \\
Attitude Strength (1-100) & 71.20 & 69.00 & 72.93 \\
Subjective norm Parents (1-100) & 56.38 & 70.94 & 70.98 \\
Subjective norm Friends (1-100) & 35.52 & 46.67 & 45.48 \\
Perceived Behavioral Control PA (1-100) & 65.39 & 74.72 & 81.17 \\
Perceived Behavioral Control Aerobic (1-100) & 73.95 & 79.61 & 81.38 \\
Perceived Behavioral Control Strength (1-100) & 69.84 & 73.94 & 71.50 \\
Intention PA (1-100) & 49.88 & 57.89 & 72.33 \\
Intention Aerobic (1-100) & 56.29 & 54.50 & 77.12 \\
Intention Strength (1-100) & 51.13 & 50.61 & 64.64 \\
Physical activity level (h/week) & 7.95 & 7.67 & 8.28
\end{tabular}

For the IAT d-600 scores: A calculated difference score $<0$ reflects a more positive implicit association with physical inactivity as compared to physical activity. A score $>0$ reflects a more positive implicit association with physical activity as compared to physical inactivity. A score of 0 reflects no, or ambivalent preferences for both physical activity and physical inactivity. For the second IAT, a score $<0$ reflects a more positive association with aerobic exercises, and a score $>0$ reflects a more positive association with strength exercises. All the pictures used can be found in Additional File 1. 


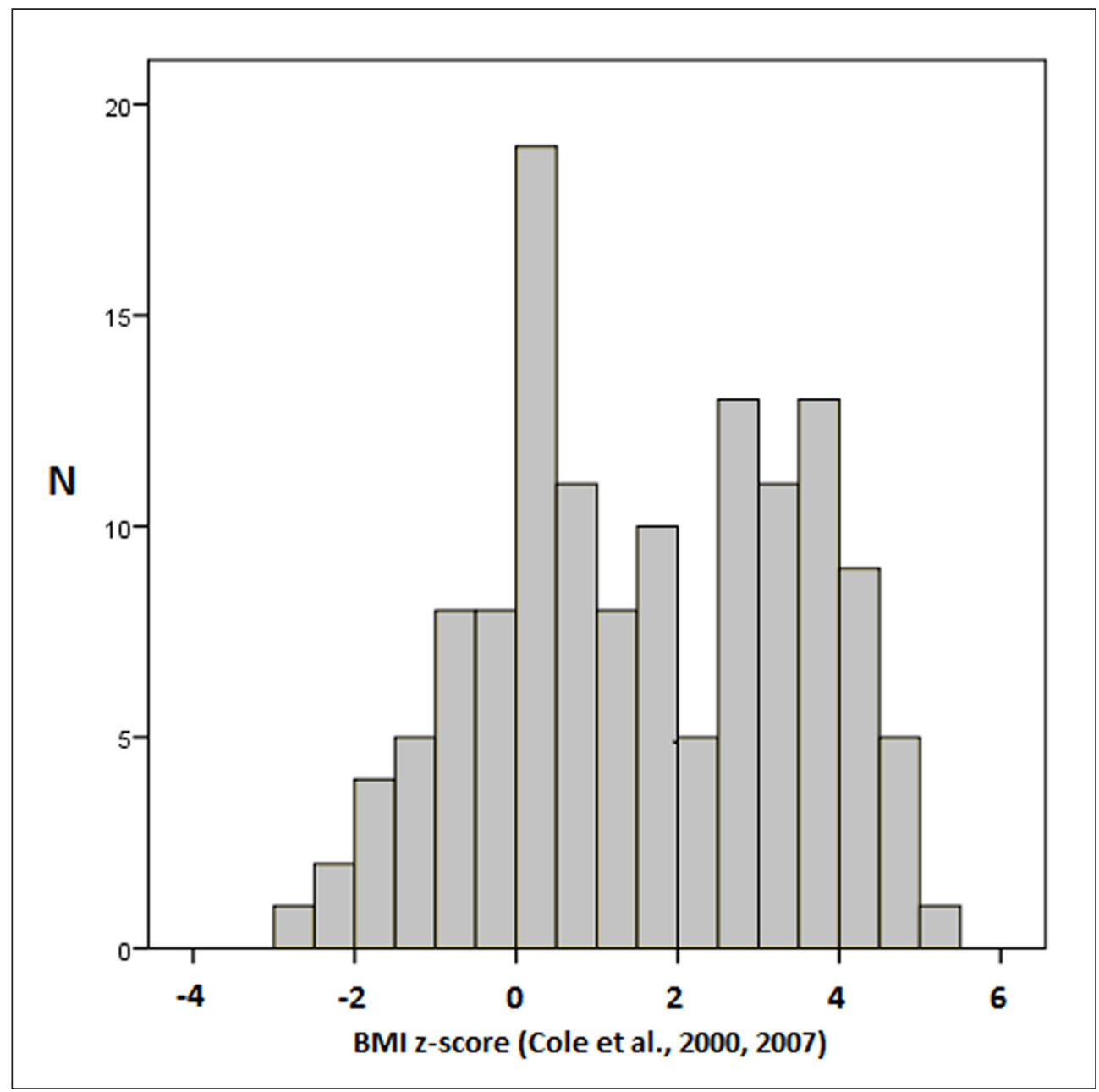

Figure 2: BMI z-score Distribution of Recruited Population (8-18 Years Old).

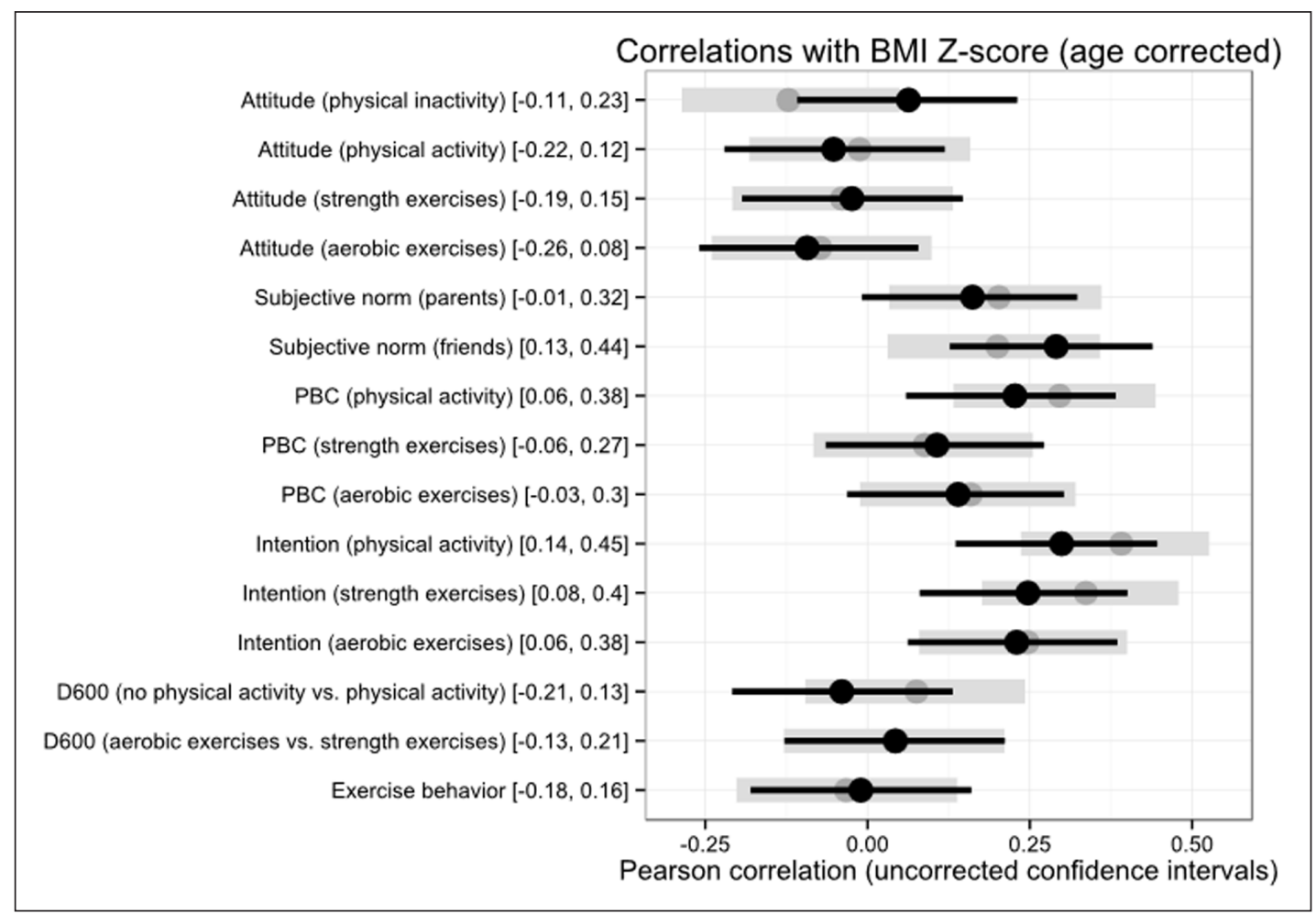

Figure 3: (Age Corrected) Correlations Between the Reflective Determinants and BMI z-scores. The black line represents the confidence intervals for the age corrected correlations; grey lines represent the uncorrected confidence intervals. 
z-scores were unrelated to subjective norms of parents $(r$ $=.16[-.01, .32], p=.16)$, they were related to subjective norms of friends $(r=.29[.13, .44], p=.01)$ : the higher the BMI z-score, the higher the perceived expectations of friends that the youngster should exercise. BMI z-scores were not related to perceived behavioral control regarding strength exercise $(r=.11[-.06, .27], p=.41)$ or aerobic exercise $(r=.14[-.03, .30], p=.25)$, but a positive correlation with perceived behavioral control related to exercise in general was found $(r=.23[.06, .38], p=.03)$ : As BMI z-scores increased, youngsters were more confident that they could be more physically active if they wanted to. BMI Z-scores were positively correlated with the three intention measures: the higher the BMI z-score, the higher the intention to be more physically active $(r=.30[.14$, .45], $p=.01)$, more engaged in aerobic exercises $(r=.25$ $[.08, .40], p=.02)$, and more engaged in strength exercises $(r=.23[.06, .38], p=.03)$. There were no differences in BMI z-scores between the self-image groups (physical inactivity vs. physical activity: Cohen's $\mathrm{d}=.01[-.34, .35], p=.98$; aerobic vs. strength: Cohen's $d=26[-0.12, .63], p=.28$, note, these are not displayed in Figure 3 due to the different metrics). BMI z-scores were not correlated to whether participants' reaction times implied stronger associations with either physical inactivity or physical activity (IAT1: $r=.09[-.21, .13], p=.75)$, or aerobic or strength exercise (IAT2: $r=.12[-.13, .21], \mathrm{p}=.75)$. No correlation between BMI z-score and self-reported physical activity was found $(r=-.01[-.18, .16], p=.91)$ (See Figure 3).

\section{Discussion}

In this study, associations between weight status and physical activity, psychosocial impulsive, and reflective determinants of exercise behavior) in youngsters (8-18 years old) (distinguishing between strength exercises and aerobic exercises were examined. Despite finding significant associations between social norms of friends, perceived behavioral control for exercise, and all three intentions, our first finding is that there are not many significant correlations between BMI z-scores and either the measured reflective determinants, or impulsive determinants (IAT scores). This may imply that a) there really are very few associations between physical activity determinants and weight status (Craeynest et al., 2005), or that b) explicitly expressed cognitions are influenced by social desirability effects (Larson, 2000). Regardless of whether the participant was recruited via the online panel or $\mathrm{COACH}$, participants with high BMI z-scores may well have been aware of the need for exercise and what is expected of them. However, the implicit measures which are not thought to be influenced by social desirability (Greenwald et al., 1998) did not show differences either, in line with the results of Craeynest et al. (2005). Moreover, inspection of the means for the three subpopulations (Table $\mathbf{1}$ ) does not suggest a systematic difference in terms of the youngsters participating in a lifestyle program giving more socially desirable answers than overweight/obese youngsters not in treatment.

What we do find is that youngsters with a higher BMI z-score are more in favor of exercise than youngsters with lower BMI z-scores: higher BMI z-scores were correlated with more positive norms for exercise (friends). They were also associated with higher perceived behavioral control for exercise and higher intentions to exercise (both aerobic and strength exercises). Youngsters with a lower BMI z-score do not have more negative correlations with exercise than youngsters with a higher z-scores in terms of concepts from current theories on reflective determinants (e.g. Montaño \& Kasprzyk, 2015). This is contrary to the findings of De Bourdeaudhuij, et al. (2005) who reported that adolescents who are overweight had less favorable psychosocial correlates related to physical activity as compared to adolescents of a normal weight (BMI cut off point $=25$ ). However, they also reported that the strength of associations between psychosocial variables and total physical activity were comparable in overweight/obese and normal weight adolescents. When we analyzed our data without correcting the BMI for age and gender, we again found few differences, but they are in the same direction as those found by De Bourdeaudhuij et al. (2005). In their sample, BMI scores were not corrected for age and gender, which makes it harder to compare the results of the two samples (Flegal \& Ogden, 2011). Moreover, in another study from the same research group (Craeynest et al., 2005) no differences were found in reflective or impulsive determinants between children with obesity and a matched control group. An alternative explanation is that the lifestyle program could reasonably be expected to raise the participants' self-efficacy for physical activity (i.e., through experience of physical activity) and their perception that their friends (e.g., from the program) think they should engage in physical activity. Resultantly, an increase in intention might also be expected. These effects could be driving the observed relationships between BMI z-score and subjective norm, perceived behavioral control, and intention. Inspection of the patterns of means in Table 1 suggests this is not the case for subjective norm but could well be the case for perceived behavioral control and intention. In both cases, it seems that the program effect might be driving most of these observed effects, but that some association might remain in the absence of this program effect.

We did not find significant correlations between BMI Z-scores and either of the two implicit measures, and only a few between BMI z-scores and reflective determinants. We expected to find a difference between strength and aerobic exercises for overweight youngsters, but we did not. One explanation for this is that in order for these youngsters to find out that they are better suited to strength exercises, they need to experience strength exercises more often (Ten Hoor et al., 2016, 2017b). Targeting strength exercises might be more effective in the long-term, as this could reinforce the biological and psychological strengths of youngsters who are overweight/obese (Ten Hoor et al., 2014, 2016). Recently, other researchers have argued along the same lines (Schranz, Tomkison \& Olds, 2013). The review by Schranz et al. (2013) about children and adolescents who are overweight provided empirical support for the (large) effects of strength training on muscle strength, in addition to the small effects of strength training on body composition. However, the effect of strength training on psychosocial outcomes remains unclear because of the limited number of studies addressing this 
topic. At least, our study does not show negative correlations with strength exercises in youngsters with a higher weight status.

\section{Limitations and implications for future research}

One of the key limitations of this study is that its design is quasi-experimental (and then specifically our sampling strategy). We recruited youngsters from two different settings in order to obtain a sufficient number of overweight and obese youngsters in the study (sampling bias). As previously mentioned, one possible explanation for the unexpected positive associations between physical activity determinants and BMI z-scores for all youngsters is that the determinants of participants from the clinic had been positively influenced by their program. Our crude matching procedure shows little indication of a sampling bias, but given there are only 18 overweight/obese participants from the general population sample, it seems likely that the tests used in the crude matching procedure were underpowered.

Based on this study, we can make several recommendations for further research. First, in future studies, objective measures of behavior should be used (see also De Bourdeaudhuij et al., 2005). Second, as there is a possibility that youngsters who are overweight or obese do not know that they are better in strength related exercises, determinants should be measured after youngsters have become exposed to and acquainted with these exercises (ten Hoor, 2018). Third, in future studies measuring actual body composition might be of additional value (Ten Hoor et al., 2018; Bogin, Varela Silva, 2012; Hunger, Tomiyama, 2014).

Lastly, to possibly achieve long-term behavior changes, evidence-based interventions should be developed, implemented, and evaluated (Bartholomew et al., 2016). The determinants of physical exercise do not differ depending on weight status, suggesting that the same kind of interventions will be effective for both groups.

\section{Conclusion}

Based on the reflective determinants, differences between normal weight youngsters and youngsters who are overweight or obese are small. Exercise intentions, including those for aerobic and strength exercises, were positively correlated with BMI z-scores. Youngsters with a higher BMI z-score often reported that their friends think they should exercise, and were more confident that they could exercise more if they wanted to. No other determinants, including impulsive determinants, were correlated with BMI z-scores, suggesting that children and adolescents with a different weight status can be targeted by the same intervention.

\section{Additional File}

The additional file for this article can be found as follows:

- Additional File 1. Research Material, Data, and SPSS Syntax. DOI: https://doi.org/10.5334/hpb.14.s1

\section{Ethics and Consent}

Participants were informed about the procedures and debriefed about the content and aim of the study after- wards, in order to minimize social desirability effects. The youngsters from the clinic and their parents signed informed consent during their monthly visit to the clinic. After parental approval was obtained, the online panel group received an invitation to participate via e-mail. The youngsters provided informed consent (by clicking on the appropriate button for the online panel). This study and consent procedure was approved by the Medical Ethics Committee of Maastricht University Medical Center+ (METC12-4-048), and the Research Ethics Board of the Faculty of Psychology and Neuroscience, Maastricht University (ECP-113-10-04-2012).

\section{Acknowledgements}

We would like to acknowledge Michiel Vestjens (Instrumentation, Faculty of Psychology and Neuroscience, Maastricht University) for programming the implicit measures and questionnaire. This project is sponsored by the Netherlands Organization for Health Research and Development (ZonMw; project number 525001004) (Grant nr 525001004).

\section{Competing Interests}

Two of the paper's co-authors, Gjalt-Jorn Peters and Gerjo Kok, are current and former editors of the journal, respectively. They were not involved in the handling of this paper through peer review or the ultimate decision to publish.

\section{Author Contribution}

$\mathrm{GtH}$ conceived of, designed, and coordinated the study, contributed to the acquisition, performed the statistical analyses, and drafted the manuscript. GK participated in the design, analysis of the data, and revision of the manuscript. GJP participated in the statistical analyses and revision of the data. GP, SK, RR, and AS participated in the design of the study and revision of the manuscript. AV participated in the acquisition and the revision of the manuscript. All authors read and approved the final manuscript.

\section{References}

Bartholomew-Eldredge, L. K., Markham, C. M., Ruiter, R. A. C., Kok, G., \& Parcel, G. S. (2016). Planning health promotion programs: an Intervention Mapping approach. 4th ed. San Francisco, CA: Jossey-Bass.

Bogin, B., \& Varela Silva, I. (2012). The body mass index: the good, the bad, and the horrid. Bulletin de la Société Suisse d'Anthropologie, 18(2), 5-11.

Cohen, J. (1990). Things I have learned (so far). American psychologist, 45(12), 1304. DOI: https:// doi.org/10.1037/0003-066X.45.12.1304

Cole, T. J., Bellizzi, M. C., Flegal, K. M., \& Dietz, W. H. (2000). Establishing a standard definition for child overweight and obesity worldwide: international survey. BMJ, 320(7244), 1240. DOI: https://doi. org/10.1136/bmj.320.7244.1240

Cole, T. J., Flegal, K. M., Nicholls, D., \& Jackson, A. A. (2007). Body mass index cut offs to define thinness in children and adolescents: international survey. BMJ, 335(7612), 194. DOI: https://doi.org/10.1136/ bmj.39238.399444.55 
Colella, D., Morano, M., Robazza, C., \& Bortoli, L. (2009). Body image, perceived physical ability, and motor performance in nonoverweight and overweight Italian children. Perceptual and Motor Skills, 108(1): 209-218. DOI: https://doi.org/10.2466/ pms.108.1.209-218

Craeynest, M., Crombez, G., Houwer, J. D., Deforche, B., Tanghe, A., \& Bourdeaudhuij, I. D. (2005). Explicit and implicit attitudes towards food and physical activity in childhood obesity. Behaviour research and therapy, 43(9): 1111-1120. DOI: https://doi.org/10.1016/j.brat.2004.07.007

De Bourdeaudhuij, I., Lefevre, J., Deforche, B., Wijndaele, K., Matton, L., \& Philippaerts, R. (2005). Physical activity and psychosocial correlates in normal weight and overweight 11 to 19 year olds. Obesity Research, 13(6), 1097-1105. DOI: https:// doi.org/10.1038/oby.2005.128

Deforche, B., De Bourdeaudhuij, I., Tanghe, A., Hills, A. P., \& De Bode, P. (2004). Changes in physical activity and psychosocial determinants of physical activity in children and adolescents treated for obesity. Patient Education and Counseling, 55(3), 407-415. DOI: https://doi.org/10.1016/j.pec.2003.07.012

Denis, D. J. (2003). Alternatives to Null Hypothesis Significance Testing. Theory Sci, 4(1), 2.

Ebbeling, C. B., Pawlak, D. B., \& Ludwig, D. S. (2002). Childhood obesity: public-health crisis, common sense cure. The Lancet, 360(9331), 473-482. DOI: https://doi.org/10.1016/S0140-6736(02)09678-2

Faigenbaum, A. D., Kraemer, W. J., Blimkie, C. J., Cameron, J. R. Jeffreys, I., Micheli, L., Nitka, M., \& Rowland, T. W. (2009). Youth resistance training: Updated position statement paper from the National Strength and Conditioning Association. Journal of Strength \& Conditioning Research, 23, S60-S79. DOI: https://doi.org/10.1519/JSC.0b013e31819df407

Flegal, K. M., \& Ogden, C. L. (2011). Childhood obesity: are we all speaking the same language? Advances in Nutrition: An International Review Journal, 2(2), 159S-166S. DOI: https://doi.org/10.3945/ an.111.000307

Gately, P. J., Cooke, C. B., Butterly, R. J., Mackreth, P., $\&$ Carroll, S. (2000). The effects of a children's summer camp programme on weight loss, with a 10 month follow-up. International Journal of Obesity Related Metabolic Disorders, 24, 1445-1452. DOI: https://doi.org/10.1038/sj.ijo.0801405

Greenwald, A. G., McGhee, D. E., \& Schwartz, J. L. (1998). Measuring individual differences in implicit cognition: the implicit association test. Journal of Personality and Social Psychology, 74(6), 1464-1480. DOI: https://doi.org/10.1037/0022-3514.74.6.1464

Greenwald, A. G., Nosek, B. A., \& Banaji, M. R. (2003). Understanding and using the Implicit Association Test: I; an improved scoring algorithm. Journal of Personality and Social Psychology, 85, 197-216. DOI: https://doi.org/10.1037/0022-3514.85.2.197

Guerra, P. H., Nobre, M. R., Silveira, J. A., \& Taddei, J. A. (2013). The effect of school-based physical activity interventions on body mass index: a meta-analysis of randomized trials. Clinics, 68(9), 1263-1273. DOI: https://doi.org/10.6061/clinics/2013(09)14

Harris, K. C., Kuramoto, L. K., Schulzer, M., \& Retallack, J. E. (2009). Effect of school-based physical activity interventions on body mass index in children: a meta-analysis. CMAJ, 180(7), 719-26. DOI: https:// doi.org/10.1503/cmaj.080966

Houben, K., \& Wiers, R. W. (2008). Measuring implicit alcohol associations via the Internet: Validation of Web-based implicit association tests. Behavior Research Methods, 40(4), 1134-1143. DOI: https:// doi.org/10.3758/BRM.40.4.1134

Hunger, J. M., \& Tomiyama, A. J. (2014). Weight labeling and obesity: a longitudinal study of girls aged 10 to 19 years. JAMA Pediatrics, 168(6), 579-80. DOI: https://doi.org/10.1001/jamapediatrics.2014. 122

Kremers, S. P., Visscher, T. L., Seidell, J. C., van Mechelen, W., \& Brug, J. (2005). Cognitive determinants of energy balance-related behaviours. Sports Medicine, 35(11), 923-933. DOI: https://doi. org/10.2165/00007256-200535110-00001

Larson, M. R. (2000). Social desirability and self-reported weight and height. International Journal of Obesity and Related Metabolic Disorders, 24(5), 663-665. DOI: https://doi.org/10.1038/sj.ijo.0801233

Liao, Y., Harada, K., Shibata, A., Ishii, K., Oka, K., \& Nakamura, Y. (2012). Correlates of physical activity among overweight and obese populations: A review of the literature. The Journal of Physical Fitness and Sports Medicine, 1(2), 325-331. DOI: https://doi. org/10.7600/jpfsm.1.325

Masicampo, E. J., \& Lalande, D. R. (2012). A peculiar prevalence of $\mathrm{p}$ values just below .05. Q J Exp Psychol, 65(11), 2271-2279. DOI: https://doi.org/10.1 080/17470218.2012.711335

Metcalf, B., Henley, W., \& Wilkin, T. (2012). Effectiveness of intervention on physical activity of children: systematic review and meta-analysis of controlled trials with objectively measured outcomes (EarlyBird 54). BMJ, 345, e5888. DOI: https://doi.org/10.1136/ bmj.e5888

Montaño, D. E., \& Kasprzyk, D. (2015). Theory of Reasoned Action, Theory of Planned Behavior, and the Integrated Behavioral Model. In K. Glanz, B. K. Rimer \& K. Viswanath (Eds.), Health behavior: Theory, research and practice (5th Ed.; pp. 168-222). San Francisco, CA: Jossey-Bass.

Morgan, P. J., Okely, A. D., Cliff, D. P., Jones, R. A., \& Baur, L. A. (2008). Correlates of objectively measured physical activity in obese children. Obesity, 16(12), 2634-2641. DOI: https://doi.org/10.1038/ oby. 2008.463

Peters, G.-J. Y. (2014). A practical guide to effective behavior change: how to identify what to change in the first place. European Health Psychologist, 16(4), 142-155.

R Core Team. (2014). R: A language and environment for statistical computing. Vienna, Austria: R Foundation for Statistical Computing. URL: http://www.Rproject.org/ 
Rhodes, R. E., Fiala, B., \& Conner, M. (2009). A review and meta-analysis of affective judgments and physical activity in adult populations. Annals of Behavioral Medicine, 38, 180-204. DOI: https:// doi.org/10.1007/s12160-009-9147-y

Riddiford-Harland, D. L., Steele, J. R., \& Baur, L. A. (2006). Upper and lower limb functionality: are these compromised in obese children? International Journal of Pediatric Obesity, 1(1), 42-49. DOI: https://doi.org/10.1080/17477160600586606

Ryan, R. M., \& Deci, E. L. (2002). An overview of selfdetermination theory: an organismic-dialectical perspective. In: E. L. Deci \& R. M. Ryan (Eds.), Handbook of self-determination research (pp. 3-33). Rochester, NY: University of Rochester Press.

Schranz, N., Tomkinson, G., \& Olds, T. (2013). What is the effect of resistance training on the strength, body composition and psychosocial status of overweight and obese children and adolescents? A systematic review and meta-analysis. Sports Medicine, 43(9), 893-907. DOI: https://doi.org/10.1007/ s40279-013-0062-9

Strack, F., \& Deutsch, R. (2004). Reflective and impulsive determinants of social behavior. Personality and Social Psychology Review, 8(3), 220-247. DOI: https://doi.org/10.1207/s15327957pspr0803_1

Ten Hoor G. A., Kok, G., Peters, G. J. Y., et al. (2017a). The psychological effects of strength exercises in people who are overweight or obese: a systematic review. Sports Medicine, 47(10), 2069-2081. DOI: https://doi.org/10.1007/s40279-017-0748-5

Ten Hoor, G. A., Plasqui, G., Ruiter, R. A., Kremers, S. P., Rutten, G. M., Schols, A. M., \& Kok, G. (2016). A new direction in Psychology and Health: Resistance exercise training for obese children and adolescents. Psychology \& Health, 31(1), 1-8. DOI: https://doi. org/10.1080/08870446.2015.1070158

Ten Hoor, G. A., Plasqui, G., Schols, A. M. W. J., \& Kok, G. (2014). Combatting adolescent obesity: an integrated physiological and psychological perspective. Current opinion in clinical nutrition and metabolic care, 17(6), 521. DOI: https://doi.org/10.1097/ MCO.0000000000000099
Ten Hoor, G. A., Plasqui, G., Schols, A. M. W. J., \& Kok, G. (2017b). Development, Implementation, and Evaluation of an Interdisciplinary Theory- and Evidence-Based Intervention to Prevent Childhood Obesity: Theoretical and Methodological Lessons Learned. Frontiers in Public Health, 22(5), 352. DOI: https://doi.org/10.3389/fpubh.2017.00352

Ten Hoor, G. A., Plasqui, G., Schols, A. M. W. J., \& Kok, G. (2018). A Benefit of Being Heavier Is Being Strong: a Cross-Sectional Study in Young Adults. Sports Medicine - Open, 4(1), 12. DOI: https://doi. org/10.1186/s40798-018-0125-4

TNO. (2011). Monitor Convenant Gezond Gewicht; beweeg- en eetgedrag van kinderen (4-11 jaar), jongeren (12-17 jaar) en volwassenen (18+ jaar) in 2010 en2011. Leiden, the Netherlands: TNO. DOI: https://doi.org/10.1007/978-90-313-7493-9_8

Trost, S. G., Kerr, L. M., Ward, D. S., \& Pate, R. R. (2001). Physical activity and determinants of physical activity in obese and non-obese children. International journal of obesity, 25(6), 822-829. DOI: https://doi. org/10.1038/sj.ijo.0801621

Van der Baan, O. H., Nollet, M. N., Weller, F. R., Benninga, M. A., \& Van Aalderen, W. M. C. (2010). Ernstige obesitas bij kinderen: een zaak van gewicht. Tijdschrift Kindergeneeskunde, 78, 106-113. DOI: https://doi.org/10.1007/BF03089886

Washington, R. L. (2008). The metabolic syndrome - no longer an adult disease. Journal of Pediatrics, 152, A1. DOI: https://doi.org/10.1016/j.jpeds.2007.12. 026

World Health Organization (WHO). (2015). Growth references 5-19 years. BMI for age (5-19 years). From: http://www.who.int/growthref/who2007_bmi_ for_age/en/ accessed: 26/6/2015.

\section{Peer Review Comments}

Health Psychology Bulletin has blind peer review, which is unblinded upon article acceptance. The editorial history of this article can be downloaded here:

- PR File 1. Peer Review History. DOI: https://doi. org/10.5334/hpb.14.pr 1

\footnotetext{
How to cite this article: ten Hoor, G. A., Plasqui, G., Kok, G., Schols, A. M. W. J., Ruiter, R. A. C., Kremers, S. P. J., Peters, G.-J. Y., \& Vreugdenhil, A. C. E. (2020). Weight-status Related Differences in Reflective and Impulsive Determinants of Physical Activity in Youngsters (8-18 years old). Health Psychology Bulletin, 4(1), 29-38. DOl: https://doi.org/10.5334/hpb.14

Submitted: 18 January 2018 Accepted: 22 May 2020 Published: 14 September 2020

Copyright: () 2020 The Author(s). This is an open-access article distributed under the terms of the Creative Commons Attribution 4.0 International License (CC-BY 4.0), which permits unrestricted use, distribution, and reproduction in any medium, provided the original author and source are credited. See http://creativecommons.org/licenses/by/4.0/.
}

] $\mathrm{u}[\quad$ Health Psychology Bulletin is a peer-reviewed open access journal published by Ubiquity Press. 